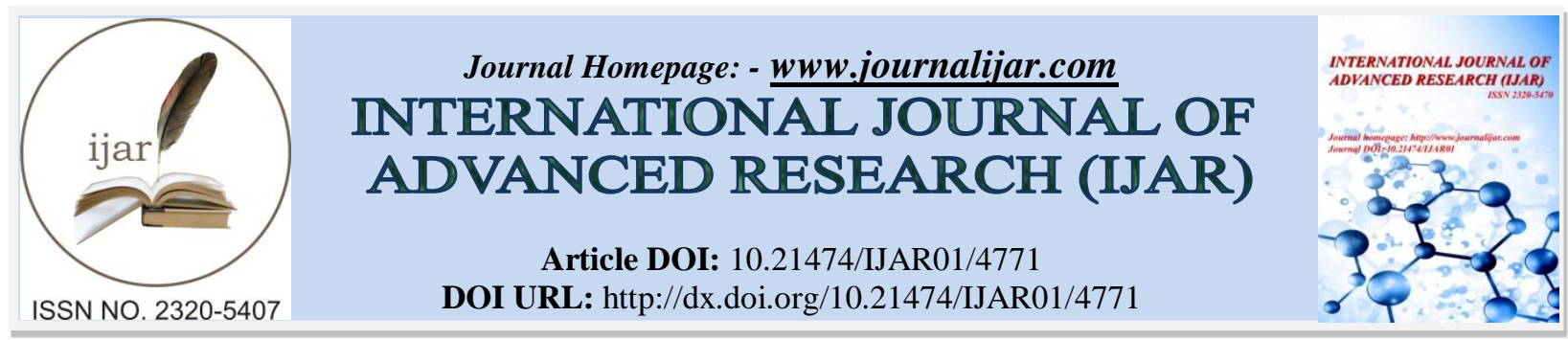

RESEARCH ARTICLE

\title{
SYNTHESIS, CHARACTERISATION AND BIOLOGICAL STUDY OF NICKEL COMPLEXES DERIVED FROM SCHIFF BASES OF P-NITRO ANILINE AND m-NITRO ANILINE WITH AROMATIC ALDEHYDES.
}

\author{
*B. B. Bahule, S. B. Kalaskar, R. P. Yadav and A. A. Purohit.
}

1. Department of Organic Chemistry, Nowrosjee Wadia College, Pune.

2. Affiliated to Savitribai Phule Pune University, Pune, Maharashtra, India.

\section{Manuscript Info}

Manuscript History

Received: 7 May 2017

Final Accepted: 9 June 2017

Published: July 2017

Key words:-

Schiff Base, Nickel complex,

Antibacterial activity

\section{Abstract}

This paper deals with the preparation of nickel complexes of Schiff bases derived from m-nitro aniline or p-nitro aniline and aromatic aldehydes. Chemical composition of these complexes was determined using FT-IR and Atomic Absorption Spectroscopy. The antibacterial activity of the Nickel complexes prove that metal containing Schiff bases show good inhibitory activity against various species of bacteria.

Copy Right, IJAR, 2017,. All rights reserved.

\section{Introduction:-}

A complex has been defined as a species formed by the association of two or much simpler species each capable of independent existence. When one of the simpler species is a metal ion, the resulting entity is known as a metal complex. There are certain metallo-elements without which the normal functioning of the living organism is inconceivable, among these metallo-elements so called, 'metals of life', four members form an 'island'. These are $\mathrm{Na}, \mathrm{Mg}, \mathrm{K}$ and $\mathrm{Ca}$. Among the transition elements are $\mathrm{V}, \mathrm{Cr}, \mathrm{Mn}, \mathrm{Fe}, \mathrm{Co}, \mathrm{Ni}, \mathrm{Cu}$ and $\mathrm{Zn}$. $\mathrm{Na}, \mathrm{Mg}, \mathrm{K}$ and $\mathrm{Ca}$ play vital roles in the living system and are present at trace and ultra-trace quantities in the cell. These are also known as 'metals of life'. These transition elements are known to form Schiff base complexes ${ }^{1}$.

Schiff bases obtained from aromatic aldehydes and aromatic amines have shown number of applications in many fields including pharmaceutical, life sciences and chemical science including inorganic and analytical chemistry $2,3,4,5$. Schiff-base complexes are considered to be among the most important stereo chemical models in main group and transition metal coordination chemistry due to their preparative accessibility and structural variety ${ }^{6}$. Schiff base compounds and their metal complexes have been extensively investigated due to their wide ranges of applications including catalysts ${ }^{7,8}$, medicine, crystal engineering, anti-corrosion agent ${ }^{9,10}$. The Schiff bases are studied widely due to their synthetic flexibility, selectivity and sensitivity towards the central metal atom; structural similarities with natural biological compounds and also due to presence of azomethine group $(-\mathrm{N}=\mathrm{CH}-)$ which imports in elucidating the mechanism of transformation and racemisation reaction biologically ${ }^{11,12}$. Schiff bases having chelation with oxygen, nitrogen etc. Donors and their complexes have been used as drugs and reported to possess a wide variety of biological activities against bacteria, fungi and certain type of tumors and also, they have many biochemical, clinical and pharmacological properties ${ }^{13,14}$.Imine or azomethine groups are present in various natural, naturally derived and non natural compounds. 
The aim of this study was to make Schiff bases of p-nitro aniline and m-nitro aniline and their complexes, followed by characterisation and antibacterial activity determination of the Schiff bases and metal complexes.

\section{Materials And Techniques:-}

Materials:-

Benzaldehyde, 4-chloro benzaldehyde, p-nitro aniline, m-nitro aniline, Sodium Hydroxide, Ethanol, Nickel chloride, petroleum ether, ethyl acetate of L.R grade Chemicals were used.

\section{Experimental Procedure:-}

Synthesis of p-nitro aniline Schiff base -I:-

The synthesis was started with $5 \mathrm{ml}$ of benzaldehyde ( 4.7 mmoles ), which was then mixed with $15 \mathrm{ml}$ alcohol.6.5 gm of p-nitro aniline ( 4.7 mmoles ) was added to this alcoholic solution. This whole mixture was stirred with addition of about 2-3 drops of aqueous sodium hydroxide. The mixture was allowed to reflux for 4 hours. After refluxing the product solidified on attaining room temperature, Alternatively a solid product can be obtained by cooling the reaction mixture in ice bath .. The product was filtered and dried and characterised by IR and AAS spectral techniques.

\section{Reaction:-}<smiles>Nc1ccc([N+](=O)[O-])cc1</smiles>

Benzaldehyde $\quad p$-nitro aniline

Schiff base I

\section{Synthesis of m-nitro aniline Schiff base - II}

The synthesis was started with $5 \mathrm{ml}$ of 4-chlorobenzaldehyde ( 3.5 mmoles ), which was then mixed with $15 \mathrm{ml}$ alcohol. $5 \mathrm{gm}$ of m-nitro aniline ( 3.6 mmoles ) was added to this alcoholic solution. This whole mixture was stirred with addition of about 2-3 drops of aqueous sodium hydroxide. The mixture was allowed to reflux for 4 hours. After refluxing the product solidified at room temperature. cold water. The product is filtered and dried for further use.

\section{Reaction}<smiles>Nc1cccc([N+](=O)[O-])c1</smiles>

Schiff base II

\section{Synthesis of metal complexes of Schiff Base:-}

Nickel chloride is used as a salt for the insertion of $\mathrm{Ni}$ in the Schiff Base. Metal chlorides are preferred as salts as they are water soluble and help in the formation of the metal complex. In this process $1 \mathrm{gm}$ of the Schiff base (derived from p-nitro/m-nitro aniline) was dissolved in $10 \mathrm{ml}$ ethanol. $1.7 \mathrm{gm}$ of Ni-chloride was added. The product was cooled and washed with cool water. The products obtained are then tried for further application. 


\section{Nickel Complex I}

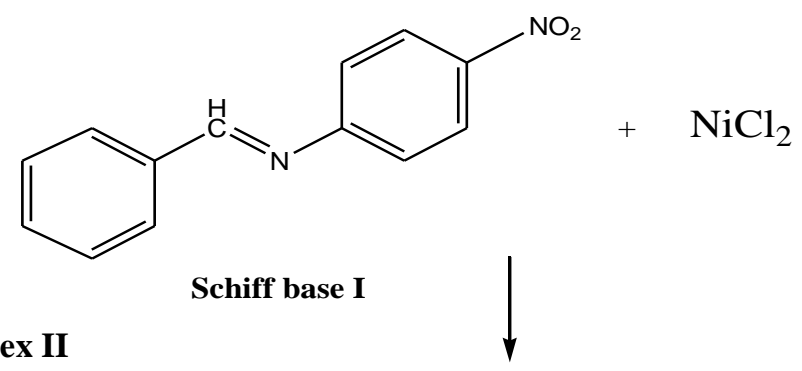

\section{Nickel Complex II}

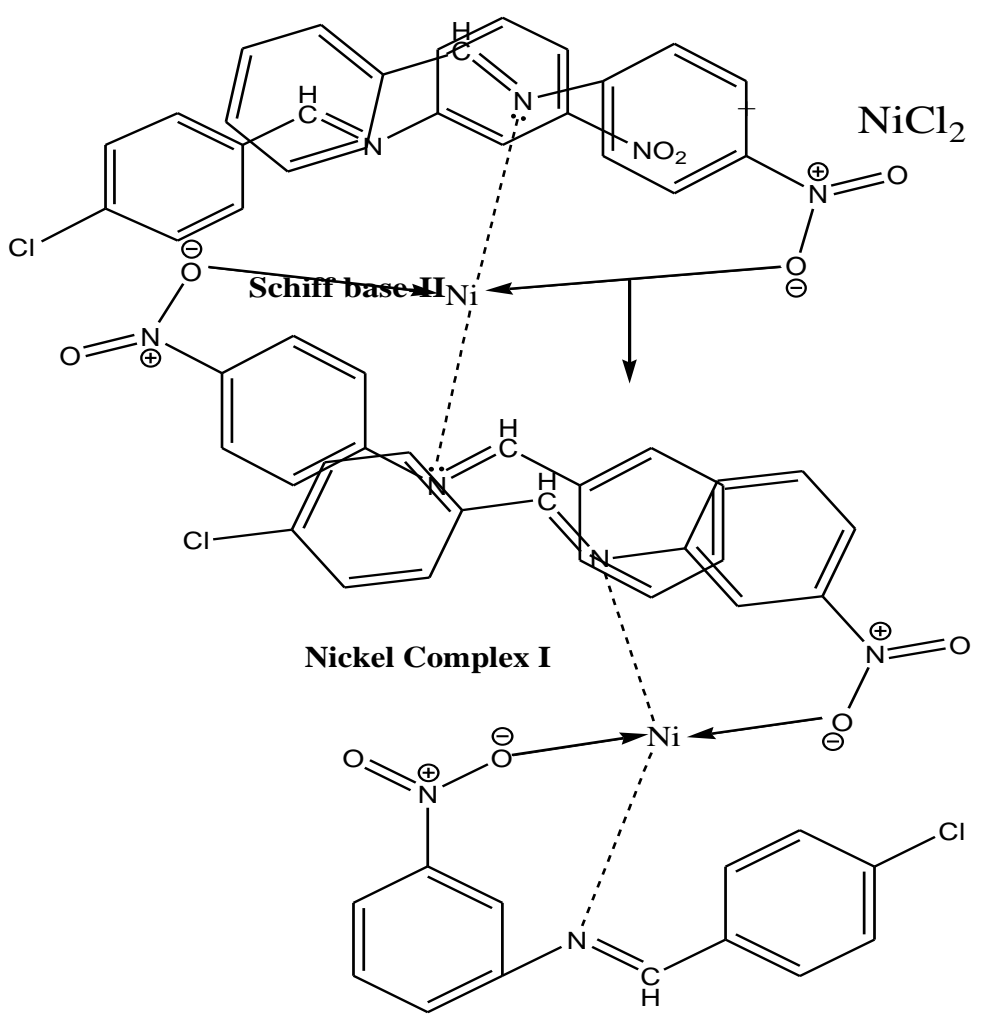

\section{Results and Discussion:-}

Nickel Complex II

Nickel complex-I : It was observed that the Nickel complex-I decomposes at $220^{\circ} \mathrm{C}$.

Nickel complex-II : It was observed that the Nickel complex-II decomposes at $240^{\circ} \mathrm{C}$ 


\section{Characterisation}

Nickel Complex-I

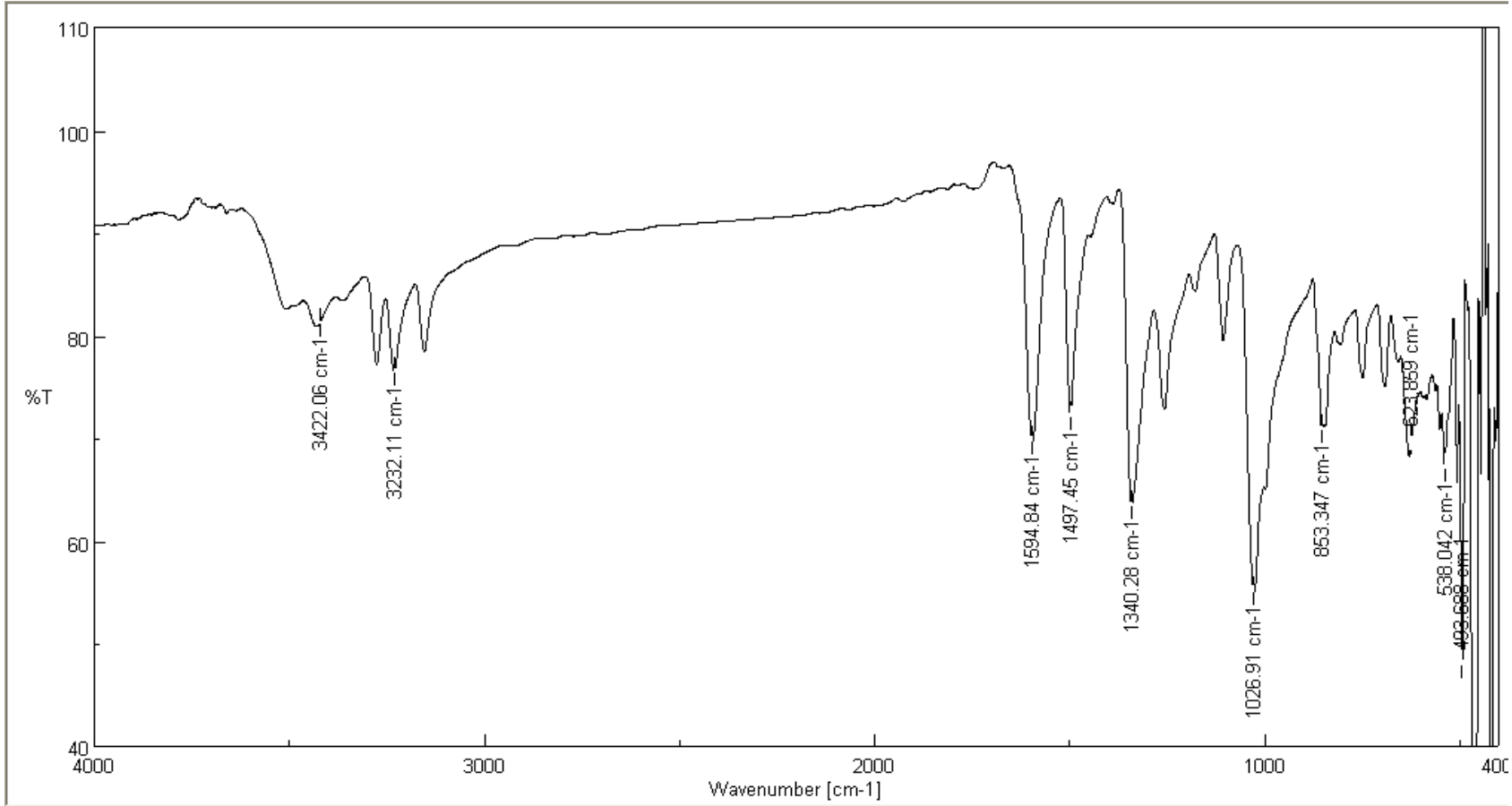

\section{FT-IR of Nickel Complex-I}

The $1497 \mathrm{~cm}^{-1}$ and $1594 \mathrm{~cm}^{-1}$ tells us about the aromatic $\mathrm{C}=\mathrm{C}$ stretching frequency in the structure. The $\mathrm{C}=\mathrm{N}$ (imine) stretching is slightly merging with one peak of the aromatic $\mathrm{C}=\mathrm{C}$ peak at $1594 \mathrm{~cm}^{-1}$. The $\mathrm{Ni}-\mathrm{O}$ bond stretching is observed at two prominent peaks in the IR spectrum at $623 \mathrm{~cm}^{-1}$ and $538 \mathrm{~cm}^{-1}$. The Ni-N co-ordinate bond gives a sharp peak at $493 \mathrm{~cm}^{-1}$ The peaks at $1340 \mathrm{~cm}^{-1}$ and $1497 \mathrm{~cm}^{-1}$ account for the presence of the $\mathrm{NO}_{2}$ (nitro) group in the sample. The peaks at $3422 \mathrm{~cm}^{-1}$ and $3232 \mathrm{~cm}^{-1}$ are unaccountable for any functional group as such and may indicate presence of some slight impurity in the sample.

\section{Nickel Complex - II}

FT-IR of Nickel Complex-II

In this complex the presence of a short peak next to $1524 \mathrm{~cm}^{-1}$ is a stretching at $1583 \mathrm{~cm}^{-1}$ which accounts for the

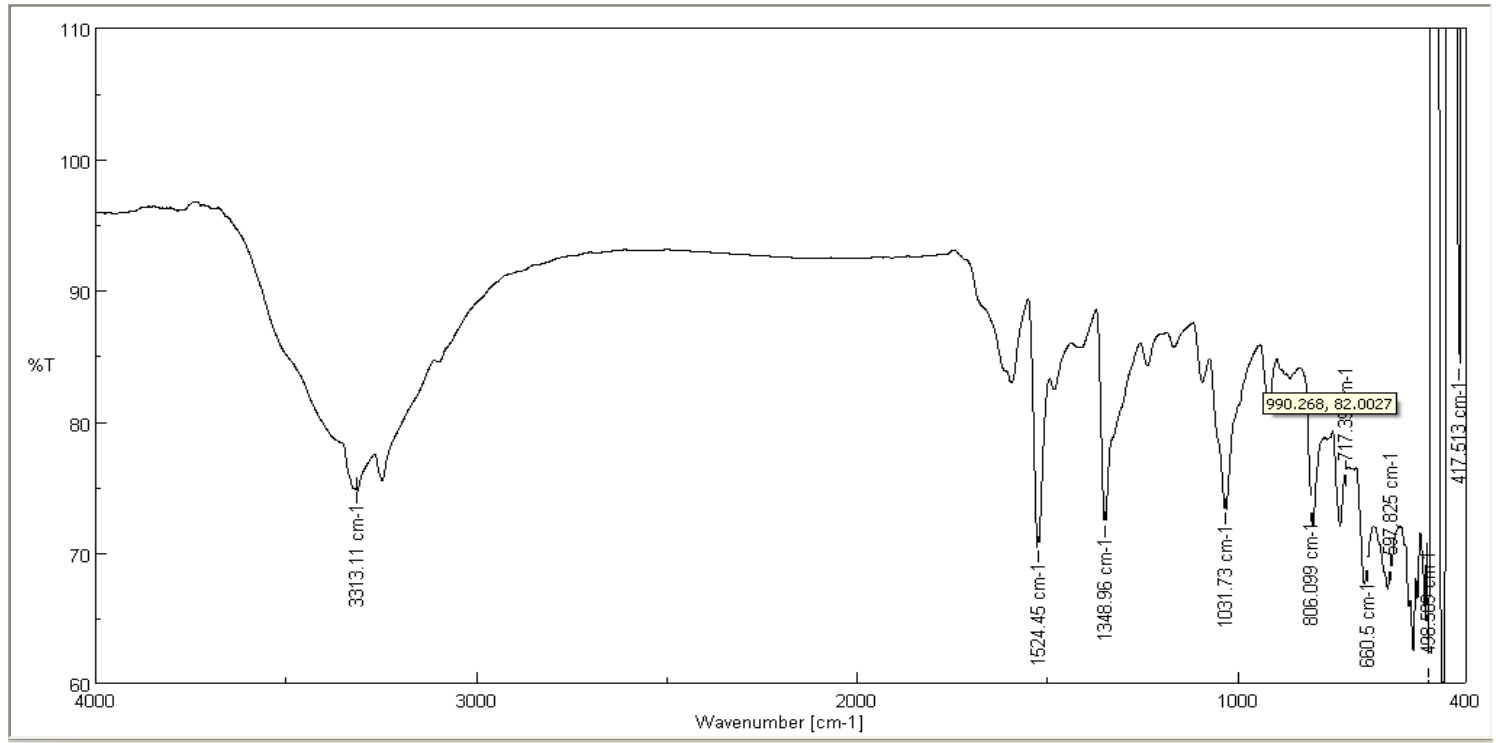


presence of two functional groups, the aromatic $\mathrm{C}=\mathrm{C}$ stretching and the $\mathrm{C}=\mathrm{N}$ (imine) stretching in the sample. The $\mathrm{Ni}-\mathrm{O}$ bond also lies in the same range as in the Nickel complex-I and gives peaks at $597 \mathrm{~cm}^{-1}$ and $660 \mathrm{~cm}^{-1}$. The Ni-N co-ordinate bond gives a peak at $498 \mathrm{~cm}^{-1}$. The peaks at $1348 \mathrm{~cm}^{-1}$ and $1524 \mathrm{~cm}^{-1}$ help us in understanding the clear presence of $\mathrm{NO}_{2}$ (nitro) group in the sample. The peak at $3313 \mathrm{~cm}^{-1}$ indicates some unknown impurity in this sample.

\begin{tabular}{|l|l|l|}
\hline $\begin{array}{l}\text { Functional group } \\
\downarrow\end{array}$ & Nickel complex-I & Nickel complex-II \\
\hline Aromatic C=C & $1497 \mathrm{~cm}^{-1} \& 1594 \mathrm{~cm}^{-1}$ & $1583 \mathrm{~cm}^{-1}$ \\
\hline $\mathbf{C}=\mathbf{N}$ & $1594 \mathrm{~cm}^{-1}$ & $1583 \mathrm{~cm}^{-1}$ \\
\hline $\mathbf{N i}-\mathbf{O}$ & $623 \mathrm{~cm}^{-1} \& 538 \mathrm{~cm}^{-1}$ & $597 \mathrm{~cm}^{-1} \& 66 \mathrm{~cm}^{-1}$ \\
\hline $\mathbf{N i}-\mathbf{N}$ & $493 \mathrm{~cm}^{-1}$ & $498 \mathrm{~cm}^{-1}$ \\
\hline $\mathbf{N O}_{2}$ & $1340{ }^{-1} \& 1497 \mathrm{~cm}^{-1}$ & $1348 \mathrm{~cm}^{-1} \& 1524 \mathrm{~cm}^{-1}$ \\
\hline
\end{tabular}

Table 1: FT-IR stretching values of Nickel complexes

\section{Atomic Absorption Spectroscopy (AAS):-}

The atomic absorption spectroscopy was done in order to prove the presence of the Nickel metal and also to determine the exact concentration of the same in both the organometallic complexes synthesised from their respective Schiff bases.

Procedure used for detection of Nickel metal: The metal complexes were partially soluble in milliQ water and $3 \mathrm{mg}$ of each sample were diluted upto $50 \mathrm{ml}$ and was subjected to the AAS . The absorbance of standard solutions of Nickel metal with concentrations of $1 \mathrm{ppm}, 3 \mathrm{ppm}$ and $5 \mathrm{ppm}$ were recorded and we observe a graph of Absorbance(y-axis) Vs Ni concentration(x-axis) of linear nature. The absorbance of the 5ppm Nickel solution was 0.138 .

The observed absorbances of sample of metal complex-I and sample of metal complex-II are 1.22 and 1.20 respectively. Due to unavailability of a higher standard solution than $5 \mathrm{ppm}$ the concentrations of both the metal complexes were calculated manually. As per the calculations done by the analyst, the concentration of metal complex-I is $44.09 \mathrm{ppm}$ and the concentration of metal complex-II is $43.57 \mathrm{ppm}$.

Graph 1:- Absorbance Vs Concentration in ppm of standard solutions of Ni solution

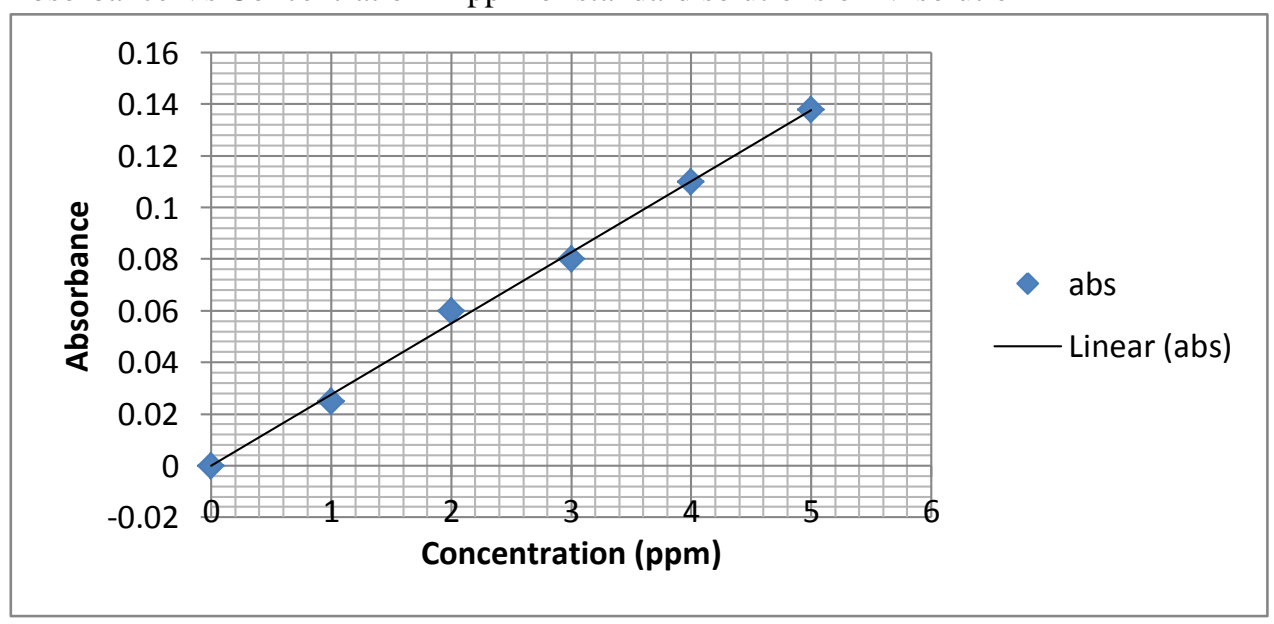

Table 2:- Concentration (in ppm) Vs Absorbance of standard Nickel solution

\begin{tabular}{|l|l|}
\hline $\begin{array}{l}\text { Concentration } \\
(\text { in } \mathbf{~ p p m ~})\end{array}$ & Absorbance \\
\hline 0 & 0 \\
\hline 1 & 0.025 \\
\hline
\end{tabular}




\begin{tabular}{|l|l|}
\hline 2 & 0.06 \\
\hline 3 & 0.08 \\
\hline 4 & 0.11 \\
\hline 5 & 0.138 \\
\hline
\end{tabular}

\section{Biological Activity:-}

Antibacterial activity:-

The increase in the mortality rate associated with infectious diseases is directly related to bacteria that exhibit multiple resistance to antibiotics. The lack of effective treatments is the main cause of this problem. The development of new antibacterial agents with novel and more efficient mechanisms of action is definitely an urgent medical need.

\section{Antibacterial assay:-}

The organisms used for this study include :

- Pseudomonas aerugenosa

- Streptococcus auerus

- Escherichia coli

- Bacillus subtilis

\section{In-vitro determination of anti-bacterial activity:-}

The stock cultures were maintained at $4^{\circ} \mathrm{C}$ on slants of nutrient agar. Active cultures for experiments were prepared by transferring a loopful of colonies from the stock culture to sterilized nutrient broth and inoculated for 24 hours at $37^{\circ} \mathrm{C}$ on shaker at 60 rotations per hour. Antibacterial activity was determined by disc diffusion method. Standard suspension of bacteria was inoculated on the surface of bacteria was inoculated on the surface of sterilized nutrient agar plates. Dimethyl sulfoxide (DMSO) as well as distilled water were used as solvents to dissolve the metal complexes in them. Sterilised filter paper $(5 \mathrm{~mm})$ containing $20 \mu \mathrm{L}$ of each extract were arranged on the surface of the inoculated plates and incubated at $37^{\circ} \mathrm{C}$ for $18-24$ hours. Along with this the control was maintained by using the discs containing $20 \mu \mathrm{L}$ of the solvents used. ie DMSO and water. After the incubation period, the inhibition zones formed around the discs were measured with scale and the results were recorded.

\section{Control experiment:-}

The control experiment was performed in order to understand that whether the solvent in which the samples were dissolved was equally active in terminating bacterial growth around the disc. The images above clearly depict that the zone of inhibitions for all the four bacterial species are not great. ie for Pseudomonas aerugenosa it is poor, for Streptococcus auerus it is least, for Bacillus subtilis it is least and for E.coli it is negative and hence helps us in deriving the conclusion that the control experiment overall is almost negative.

The observations for the biological activity of the metal complexes when they were dissolved in distilled water were clearly negative as there was no zone of inhibition in any of the bacterial species considered for the biological activity.

The observations for the biological activity when the sample was dissolved in dimethyl sulfoxide (DMSO) clearly indicate zones of inhibition in Bacillus subtilis, Streptococcus, Pseudomonas aeruginosa and E.coli.

\section{Nickel complex I}

For Bacillus subtilis the zone of inhibition is roughly moderate $(4 \mathrm{~mm})$, for Streptococcus auerus also the zone of inhibition is again moderate ( $3 \mathrm{~mm})$, for Pseudomonas aerugenosa the zone of inhibition can be accounted as a good zone of inhibition (5mm), for E.coli the zone of inhibition is again moderate (4mm).

\section{Nickel complex II}

For Bacillus subtilis the zone of inhibition is less $(1 \mathrm{~mm})$, for Streptococcus auerus too the zone of inhibition is less $(1 \mathrm{~mm})$, for Psuedomonas aerugenosa the zone of inhibition can be considered as moderate $(3 \mathrm{~mm})$, E.coli also shows moderate zone of inhibition $(3 \mathrm{~mm})$. 
Table 3:- Comparative study of biological activity observed

\begin{tabular}{|c|c|c|c|c|}
\hline & Bacillus subtilis & Streptococcus auerus & $\begin{array}{l}\text { Pseudomonas } \\
\text { aeruginosa }\end{array}$ & E.coli \\
\hline Distilled Water & $0 \mathrm{~mm}$ & $0 \mathrm{~mm}$ & $0 \mathrm{~mm}$ & $0 \mathrm{~mm}$ \\
\hline DMSO & $0.5 \mathrm{~mm}$ & $1 \mathrm{~mm}$ & $2 \mathrm{~mm}$ & $0 \mathrm{~mm}$ \\
\hline $\begin{array}{l}\mathrm{Ni} \quad \text { complex-I } \\
(\mathrm{F})(5 \mathrm{mg} / \mathrm{ml})\end{array}$ & $4 \mathrm{~mm}$ & $3 \mathrm{~mm}$ & $5 \mathrm{~mm}$ & $4 \mathrm{~mm}$ \\
\hline $\begin{array}{l}\mathrm{Ni} \quad \text { complex- } \\
\text { II }(\mathrm{B})(5 \mathrm{mg} / \mathrm{ml})\end{array}$ & $1 \mathrm{~mm}$ & $1 \mathrm{~mm}$ & $3 \mathrm{~mm}$ & $3 \mathrm{~mm}$ \\
\hline
\end{tabular}

Calculation of exact zone of inhibition of Nickel complexes

Exact zone of inhibition of Nickel complex $=$ Zone of inhibition of Nickel

- zone of inhibition in DMSO (control)

complex

Table 4:- Exact zones of inhibition of both Nickel complexes

\begin{tabular}{|l|l|l|l|l|}
\hline Complex & Bacillus subtilis & Streptococcus auerus & $\begin{array}{l}\text { Pseudomonas } \\
\text { aeruginosa }\end{array}$ & E.coli \\
\hline Nickel complex-I(F) & $3.5 \mathrm{~mm}$ & $2 \mathrm{~mm}$ & $3 \mathrm{~mm}$ & $4 \mathrm{~mm}$ \\
\hline Nickel complex-II(B) & $0.5 \mathrm{~mm}$ & $0 \mathrm{~mm}$ & $1 \mathrm{~mm}$ & $3 \mathrm{~mm}$ \\
\hline
\end{tabular}

Conclusion:-

Characterisation:-

FT-IR:

The peaks in both the FT-IR graphs confirm the presence of the aromatic $\mathrm{C}=\mathrm{C}$ region, $\mathrm{C}=\mathrm{N}(\mathrm{imine})$, the metaloxygen $(\mathrm{Ni}-\mathrm{O})$ and the metal-nitrogen $(\mathrm{Ni}-\mathrm{N})$ bond which also tells us the complete formation of the organometallic complex derived from the Schiff base. The presence of $\mathrm{NO}_{2}$ (nitro) group is also confirmed in graphs of both the samples.

Atomic absorption spectroscopy:-

After performing the Atomic Absorption Spectroscopy, we estimate the exact Nickel metal concentration(ppm) in both the samples. ie metal complex-I and metal complex-II and also prove that the metal present in both the samples is Nickel.

\section{Biological activity:-}

In relevance with the biological activity done there are a few conclusions derived from them and a few points are taken into consideration after the comparative study of the results of the control experiment, the negative results obtained when distilled water is used and the positive results obtained when DMSO is used to dissolve the samples.

\section{Nickel Complex-I}

The Nickel complex-I was found to have moderate zone of inhibition in all the bacterial species studied. The zone of inhibition was found to be the highest in E.coli which was $4 \mathrm{~mm}$ followed by Bacillus subtilis (3.5mm), Pseudomonas aerugenosa $(3 \mathrm{~mm})$, the least zone of inhibition was observed for this particular Nickel complex-I is Streptococcus auerus $(2 \mathrm{~mm})$. 


\section{Nickel complex-II}

The Nickel complex-II was found to have positive activity in E.coli $(3 \mathrm{~mm})$ as it showed moderate inhibition, while Pseudomonas aueroginosa $(1 \mathrm{~mm})$ and Bacillus subtilis $(0.5 \mathrm{~mm})$ showed least inhibition. The complex showed no activity against Streptococcus auerus $(0 \mathrm{~mm})$

After comparing the results of both the Nickel complexes we see that the Nickel complex-I derived from Schiff Base-I i.e. p-nitro aniline and benzaldeyde has a more dominant activity than the Nickel complex-II derived from Schiff Base-II ie. m-nitro aniline and 4-chlorobenzaldehyde.

\section{Acknowledgement:-}

The authors are thankful to the Principal Nowrosjee Wadia College Pune for providing the necessary infrastructure and constant encouragement. We are also thankful to Savitribai Phule Pune University for assistance in recording the spectral data.

\section{References:-}

1. Solís-Calero C, Ortega-Castro J, HernándezLaguna A, Muñoz F. A.,(2012), Theor Chem Acc. 131,9,1263.

2. Bader, N. R., (2010) A review Rasayan J. Chem. 3, ,660.

3. Satyanarayana, V. S. V, Sreevani, P., Sivakumar, A. and Vijayakumar, V. S., (2008), Arkivoc, 17, ,221.

4. Patel, V., Trivedi, P., Gohel, H. and Khetani, D., (2014), Int. J. Adv. Pharmacy, Biol. Chem. 3, ,999.

5. Ashraf, M. A., Mahmood, K., Wajid, A., Maah, M. J. and Yusoff, I., (2011), Int. Conf. Chem. adn Chem. Process 10,1 .

6. H. Keypour, M. Rezaeivala, L. Valencia, P. Perez Lourido and H. Raza Khavasi, (2009),Polyhedron, $28,3755$.

7. K. C. Gupta and A. K. Sutar., (2008),Coordination Chemistry Reviews, 252, 12-14, 1420.

8. P. G. Cozzi., (2004), Chemical Society Reviews, 33,7, 410.

9. I. Ahamad, R. Prasad and M. A., (2010),Corrosion Science, 52, 3, 933.

10. M. Antonijevic and M. Petrovic., (2008), International Journal of Electrochemical Science, 3,1, 1.

11. H. Sharghi and M. A. Nasseri., (2003), Bulletin of the Chemical Society of Japan, 76,1, 137.

12. W. T. Gao and Z. Zheng., (2002), Molecules, 7, 7, 511.

13. G. Bringmann, M. Dreyer, J. H. Faber, P. W. Dalsgaard, D. Staerk and J. W. Jaroszewski., (2004),Journal of Natural Products, 67, 5, 743.

14. Z. Y. Guo, R. Xing, S. Liu, Z. Zhong, X. Ji, L. Wang and P. C., (2007),Carbohydrate Research,342, 10, 1329. 